\title{
Physicochemical Properties and Metal Ions in Water and Sediment of the Dhaleshwari River
}

\author{
Md. Mazharul Islam, Md. Hossan Sohid Shoraoardy Bhuiyan, Rakibul Islam, Mohammad Shoeb*, Md. Iqbal \\ Rouf Mamun and Md Hafizur Rahman
}

Department of Chemistry, University of Dhaka, Dhaka-1000, Bangladesh

(Received: 27 September 2020; Accepted: 24 February 2021)

\begin{abstract}
This study was aimed to measure sediment and water quality parameter such as moisture and ash content, $\mathrm{pH}$, TOC, TSS, BOD, TOC, DO, Electrical Conductivity (EC) and $\mathrm{Na}, \mathrm{K}, \mathrm{Ca}$ and $\mathrm{Cr}$ metal ions from Dhaleshwari River close to the Savar Tannery Estate (STE). The moisture and ash content of sediments were $23.45-31.42 \%$ and $2.09-5.80 \%$, respectively. The pHs of sediment and water samples were 5.20-6.21 and 7.68-8.03, respectively. The average of Ca-hardness, DO and BOD in water were 885.9 \pm 88.8 , $1.80 \pm 0.10$ and $16.70 \pm 1.43 \mathrm{mg} / \mathrm{L}$, respectively. The EC of the sediment and water were $24.60-374.00 \mu \mathrm{S} / \mathrm{cm}$ and $32.80-39.50$ $\mathrm{mS} / \mathrm{cm}$, respectively. The amount of TOC in sediment and water samples were $1.29-3.25 \mathrm{~g} / 100 \mathrm{~g}$ and $2.28-2.70 \mathrm{mg} / \mathrm{kg}$ which are very low indicating the fewer amounts of plant and animal residues and sediment biota. TSS in water was $776-936 \mathrm{mg} / \mathrm{L}$ which is higher than the permissible limit $(600 \mathrm{mg} / \mathrm{kg})$. The $\mathrm{Cr}$ content was determined by AAS which implies that the sediment has significantly higher $\mathrm{Cr}$ content $(38.78-681.62 \mathrm{mg} / \mathrm{kg})$ compared to water $(<0.005 \mathrm{mg} / \mathrm{L})$. The amount of $\mathrm{Na}$ and $\mathrm{Ca}$ ions were 26.81-45.00 and 16.04-27.36 mg/L, respectively while $\mathrm{K}$ ion was very negligible in water.
\end{abstract}

Keywords: Tannery industries, Water quality, Sediment quality, Physicochemical parameters, Dhaleshwari River, Pollutants

\section{Introduction}

Raw hides are processed into leather in tanneries for manufacturing different products like shoe, belt, bags, suitcase, jacket, wallet which are high in quality and meet the demand of our own and foreign countries. ${ }^{1}$ Tannery industry is entirely run by raw materials available locally like buffalo and cow hides, goat and sheep skins. However, tannery waste can cause serious environmental pollution. Industrialization in the bank of river is one of the major sources of river pollution. ${ }^{2}$ It is now a global issue beyond Bangladesh. Tannery industries are the largest producer of hazardous wastes through leather tanning to its finished products. ${ }^{3}$ Both the persistent and non-persistent pollutants like as chlorides, sulphate, sulphides, lime, chrome salts, tannins including some organic pollutants as well as dyes, finishing agents, newer synthetic chemicals for processing, etc associated with the threat of human health and environment are discharged from the tanneries. ${ }^{4-7}$ Because of the discharge of these wastes into the nearby land, these can be leached and spread into the water bodies and contaminate environment. ${ }^{8,9}$ High salinity, High organic and inorganic chemicals, and $\mathrm{Cr}$ levels are the index of tannery waste and those degrade the quality of environment. ${ }^{10,11}$ Recently, tannery estate has been relocation from Hazaribagh to Savar area close to the Dhaleshwari river in order to avoid the pollution of the Buriganga River.

But the Dhaleshwari River is now started to suffering from pollution due to the lack of proper technologies for cleaning tannery effluents and proper recycling. At the same time it pushes the tannery workers to the serious health jeopardy. ${ }^{12}$ It was reported in the daily newspaper that before relocation tannery killed the Buriganga and after relocation it is killing the Dhaleshwari and its ecosystem (Figure 1). ${ }^{13-16}$ The same scenario is repeating, causing the river death and public health in danger and pulverize the fishing system in the

river. Since both the sediment and water are very important part of our environment, the main purposes of our present study are to quantitative determination of different physicochemical parameters such as moisture content, ash contents, pH, DO (Dissolved Oxygen), BOD (Biological Oxygen Demand), TOC (Total Organic Carbon), EC (Electrial Conductivity) for both the sediment and water quality of Dhaleshwari River.

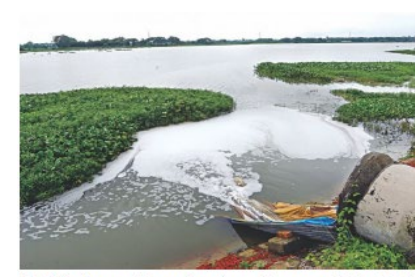

(a) Discharge from the Savar Tannery Industrial Estate creates a thick foam in the Dhaleshwari river

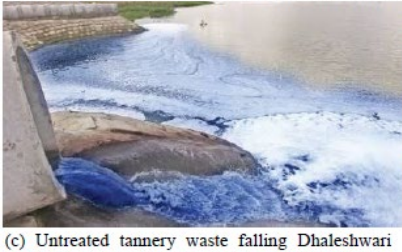

(c) Untreated tannery waste falling Dhaleshwari
causes serious damage to biodiversity of the rever

Fig. 1. Tannery waste polluting Dhaleshwari River $\left(a^{13}, b^{14}, c^{15}\right.$
and $\left.d^{16}\right)$

\section{Experimental}

20 water and 20 sediment samples were collected (August, 2019) from the Dhaleshwari River at Jhauchor near Savar in Dhaka. The locations were selected as it covers a range of few meters to several kilometers. Water samples were collected using plastic sampling bottles and sediment samples in polythene bags with proper leveling (Table 1 and 2) stored at $-4{ }^{0} \mathrm{C}$. The instruments used were $\mathrm{pH}$ meter (Model: JENWAY 3510), EC meter (Model: JENWAY 4510), TOC analyzer (Model: TOC-VCPH, Shimadzu, 
Japan), Basic titration glass apparatus, Incubator and multi parameter instrument (Model: session 156, Hach), AAS (Model: 6800, Shimadzu), Vortex machine (Model: KEBO Lab REAX-2000).

\section{Physicochemical Parameters}

The $\mathrm{pH}$ of the water samples were measured with a $\mathrm{pH}$ meter at $25-30^{\circ} \mathrm{C}$ (Table 1). Intense fluctuation of $\mathrm{pH}$ threatens the aquatic life whether it can be acidic, basic or neutral. ${ }^{17}$ Sediment sample was mixed with distilled water at 1:10 into a $50 \mathrm{~mL}$ Teflon tube and vortexed for $5 \mathrm{~min}$. Then it was centrifuged and filtered for $\mathrm{pH}$. The $\mathrm{EC}$ of water is an index of salt content and it is the ability of water to conduct electricity which was measured with a conductivity meter. ${ }^{18}$ To determine EC of sediment, it was mixed with distilled water at 1:10 into a $50 \mathrm{~mL}$ Teflon tube and vortex for $5 \mathrm{~min}$. Then it was centrifuged and filtered for EC. TOC in water was measured in Centre for Advanced Research in Sciences (CARS), Dhaka University by TOC analyzer. TOC in a sediment sample was determined by Walkley and Black's Wet oxidation method. The oxidation was done by weighing $2 \mathrm{~g}$ air dried sample passing through a 75-mesh sieve into a $500 \mathrm{~mL}$ conical flask. $10 \mathrm{~mL}$ of standard $0.5 \mathrm{M} \mathrm{K} \mathrm{K}_{2} \mathrm{Cr}_{2} \mathrm{O}_{7}$ and $20 \mathrm{~mL}$ conc. $\mathrm{H}_{2} \mathrm{SO}_{4}$ was added and mix thoroughly about $30 \mathrm{~min}$. for completing the reaction. Then $200 \mathrm{~mL}$ distilled water was added for dilution. $10 \mathrm{~mL}$ of orthophosphoric acid or $0.2 \mathrm{gof}$ $\mathrm{NaF}$ powder and $2 \mathrm{~mL}$ of diphenylamine indicator were added. A deep violet color was appeared. Then titration was done with standard $\mathrm{FeSO}_{4}$ solution till the color changes from violet to blue and finally bright green or bottle green and recording the volume of ferrous sulphate needed. A blank titration was carried out (without sediment) in same way. Calculation was done as, Organic carbon $\%$ in sediment $=(\mathrm{X}-\mathrm{Y}) \mathrm{ml} \times 0.003 \times 100 \div 2 \times \mathrm{W}=\mathrm{Z}$

Organic carbon $\%$ in sediment $=\mathrm{Z} \times 1.3=\mathrm{R}$, Where, $\mathrm{X}=$ blank titration reading, $\mathrm{Y}=$ sample reading, $\mathrm{W}=\mathrm{Weight}$ of sediment used. Assume that organic matter contains 58\% carbon, thus the organic matter content of the sediment will be calculated as Organic matter in sediment $(\%)=\mathrm{R} \times 1.724$

The hardness of water was measured by titrimetric method. DO and BOD of water samples were measured using a BOD incubator and a multi parameter analyzer (Model: Session 156, Hach). BOD implies the presence of biologically active living systems in the water body that use DO and reduce the amount of it in water. ${ }^{19}$ TSS test is performed by Whatman 934-AH glass microfiber filter (or equivalent) which has pore size of $1.5 \mathrm{~mm}$ and a predetermined volume usually $0.1 \mathrm{~L}$ is passed through it. The filter is weighed before the sample is filtered, and after the filter is dried to a constant weight at $103-105^{\circ} \mathrm{C}$. Certain amount of sediment sample was taken into pre-cleaned, weighed and dried crucible and placed them into the furnace. To determine moister content sample was heated for 4 hours at $105{ }^{\circ} \mathrm{C}$, then cooled and weighed and from that we got moisture content. Finally, these samples were heated for another 6 hours at $700{ }^{\circ} \mathrm{C}$ to determine ash content in sediment samples.

Metal ions were measured by flame AAS. Samples were aspirated through nebulizer and absorbance was measured with a blank as reference. At first standard solution of different concentration was prepared for individual elements. 10 water samples were analyzed for $\mathrm{Cr}$ at the laboratory of Bangladesh Council of Scientific and Industrial Research (BCSIR), Dhaka, Bangladesh. For analysis of $\mathrm{Cr}$ in sediment, samples were dried and then microwave digestion was carried out. The digestion was done by weighing about $0.5 \mathrm{~g}$ of sample into each vessel then $10 \mathrm{~mL}$ of conc. $\mathrm{HNO}_{3}$ was added followed by $1 \mathrm{~mL}$ of $\mathrm{H}_{2} \mathrm{O}_{2}$ and stand about $15 \mathrm{~min} .{ }^{20}$ When the initial reaction between the acids and the samples subsided, all vessels were tightly sealed with screw caps and placed in the microwave. For this program, no cooling step was used and microwave digestion was carried out for 30 min. at $180^{\circ} \mathrm{C}$. After digestion, the content in the vessels were poured into clean $50 \mathrm{~mL}$ plastic tubes and diluted with MilliQ-water up to $50 \mathrm{~mL}$. In this study, a statistical calculation, called Pearson Correlation matrix, is done to correlate the physicochemical parameters analyzed in sediment and water.

\section{Results and Discussion}

20 water and 20 sediment samples of Dhaleshwri River were analyzed (Table 1-3). $\mathrm{pH}$ of waters were 7.68-8.03 indicating slightly alkaline in nature while $\mathrm{pH}$ of sediment samples were 5.20-6.21 accounting for moderately acidic to slightly acidic in nature. The presence of hydrogen carbonate, carbonates, borates, silicates, phosphates and free hydroxyl ions are responsible for the basic nature of the tannery waste and natural water. ${ }^{21,22}$ The standard limit of $\mathrm{pH}$ for water is 6.5-8.5 which indicates the level of $\mathrm{pH}$ of the samples are in recommended level. ${ }^{23,24}$ Alkalinity of water depends on different salts or anions (chloride, bromide etc.), metal ions or alkaline earth metal elements that form $\mathrm{OH}^{-}$when dissolved in water. The acceptable sediment $\mathrm{pH}$ for most plants is 6.00-7.50, as nutrients are available in this range ${ }^{25}$ whereas according to USDA (1998), a pH of 6.60-7.30 is favorable for microbial activities that contribute to the availability of $\mathrm{N}, \mathrm{S}$, and $\mathrm{P}$ in sediments. ${ }^{26}$ Thus, the $\mathrm{pH}$ data are within the close vicinity of reported values. ${ }^{26}$ The EC implies the overall ionic species in the water ${ }^{17}$ and this study reports as $32.80-39.50$ $\mathrm{mScm}^{-1}$ with the average value of $36.15 \mathrm{mScm}^{-}{ }^{1}$ (Table 1 ). The higher EC indicate the higher amount of ions in the water. The moderate EC indicate the good numbers of ions present in water. The EC values of water are above the standard level $\left(3 \mathrm{mScm}^{-1}\right)$ (Table 1$)^{27,28}$ due the ionic chemicals or high amount of acid, base and salt in the river water from tannery waste ${ }^{21,29}$ that causes incompatibility of availability free metal ions for living organism in the water body. $^{21,30}$ The EC of sediment is an indication of the presence of water-soluble ions. Most importantly to fertility, EC is an indication of the availability of nutrients in the sediment. The EC of the sediment samples was 
24.60-374.00 $\mu \mathrm{Scm}^{-1}$ (Table 2) that indicates tannery discharge the soluble salt waste into the land. All the values are below the standard level $2210 \mu \mathrm{S} / \mathrm{cm}^{10}{ }^{10}$ Too low EC levels indicate low available nutrients, and too high EC levels indicate an excess of nutrients. The range of TOC was $2.28-2.70 \mathrm{mg} / \mathrm{L}$ with mean value $2.48 \pm 0.11 \mathrm{mg} / \mathrm{L}$ for water samples indicating low TOC in water implies water might contain fewer amounts of plant and animal residues, root exudates, living and dead microorganisms, and sediment biota, organochlorine pesticide, Persistent Organic Pollutants (POPs) etc. Direct release of ternary and other industrial waste into environment can also dramatically increase the value of TOC.

The TOC of sediment was determined by simple Walkley and Black's Wet oxidation method. ${ }^{31}$ TOC of sediment was 1.29-3.25\% (Table 2). The lower amount of organic matter in other sediment samples might be due to lower amount of organic pesticides was deposited. The Hardness of water was $740-1048 \mathrm{mg} / \mathrm{L}$ which is higher as normal surface river water. An acceptable range for free calcium in culture waters is $25-100 \mathrm{mg} / \mathrm{L}{ }^{32}$ The high hardness values indicate the abundance of lime stone and other alkaline materials discharged from the tannery industries. For water samples, the DO was $1.61-1.99 \mathrm{mg} / \mathrm{L}$. The permissible standard limit of DO is above $4.5-8 \mathrm{mg} / \mathrm{L}$ according to Bangladesh Atomic Energy Commission and $4.5 \mathrm{mg} / \mathrm{L} .{ }^{33}$ Low DO level of all water samples indicates that these systems are not well oxygenated. BOD of water was 14.20-19.50 mg/L (Table 1). The higher values of BOD are an indicator of polluted quality water due to the waste disposal from tanneries and dairy industries, while a low BOD indicates

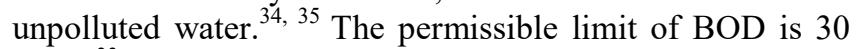
$\mathrm{mg} / \mathrm{L} .{ }^{33}$ All data are below this standard limit, so there are insignificant amount of organic substance present in the river water which is still in suitable condition for fisheries. ${ }^{36}$ But the result in depletion of aquatic DO, and fish and aquatic insects may die when oxygen is depleted by microbial metabolism which increases the BOD over the standard value. The TSS were $776-936 \mathrm{mg} / \mathrm{L}$ with an average of $872 \pm 37.44 \mathrm{mg} / \mathrm{L}$ (Table 1 ) which is much more higher than the surface river water. TSS causes turbidity in water disrupting photosynthetic action in aquatic flora. ${ }^{37}$ The standard limit of TSS for waste water is $600 \mathrm{mg} / \mathrm{L}$ and all the studied data transcend this limit. ${ }^{33}$ High-level dumping of carbonates, bicarbonates and chlorides salt of $\mathrm{Ca}, \mathrm{Mg}$ and $\mathrm{Na}$ from industries causes opaqueness. ${ }^{38}$

Both moisture and ash contents of sediment were determined by simple gravimetric method to get an idea about physical and chemical behavior of sediment and these varies place to place and in some place ash content is relatively higher than others. The moisture content was $23.45-31.42 \%$ and the ash content was $2.09-5.80 \%$. Cr found in all sediment samples as $38.78-681.62 \mathrm{mg} / \mathrm{kg}$. M.N. Mondol reported the moisture content of sediment as $18-28$ and $22-36 \%$ in dry season and wet season, respectively, at various sampling points of Hazaribagh area. ${ }^{39}$ Our results are also close to these values in Savar tannery zone. The concentration of $\mathrm{Cr}$ in sediment was 38.78-681.62 mg/L. Approximately, all the leather production globally follows the chrom-tanning, than vegetable tanning, where salts of chromium like chromium sulphate are widely used. ${ }^{40,41} \mathrm{Md}$. Abdul Mottalib reported that $\mathrm{Cr}$ in tannery wastewater contaminated sediment of leather industrial areas of Dhaka as $994-1120 \mathrm{mg} / \mathrm{L}$ in dry sediment. $^{42}$ This concentration is higher enough than $\mathrm{Cr}$ in water because dumping of tannery wastes in land is now a general habit of the industries. The world standard limit for $\mathrm{Cr}$ in sediment is $70 \mathrm{mg} / \mathrm{L} .{ }^{43}$ From Table 2, it is clear that more than fifty percent of the samples are below this limit. This may be due to the fact as the water flows downstream, the dilution effect increases; as a result $\mathrm{Cr}$ concentration gradually decreases away from main ditch.

Table 1. Water quality parameters of the water samples collected from River side area

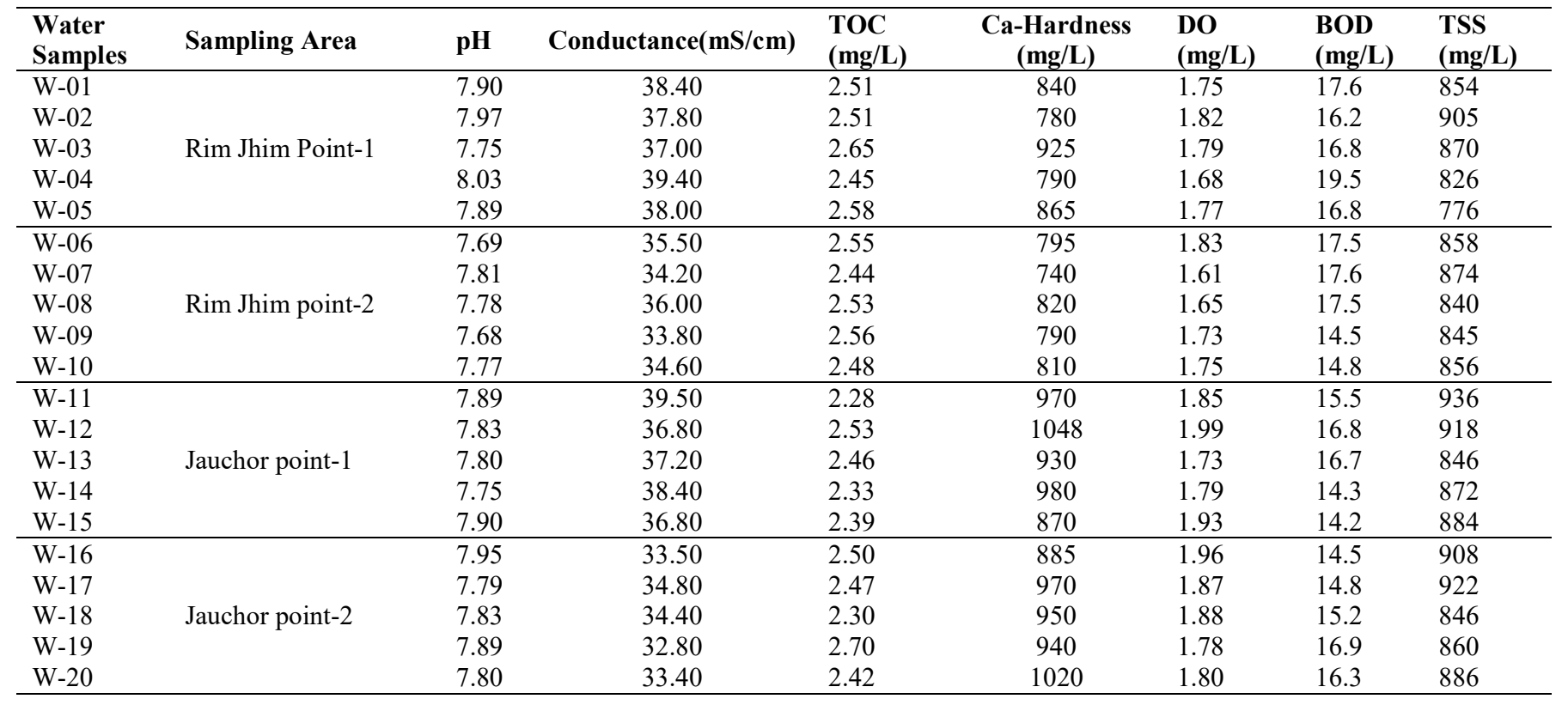


Table 2. Sediment quality parameters and $\mathrm{Cr}$ content of the sediment samples collected from River side area

\begin{tabular}{|c|c|c|c|c|c|c|c|}
\hline $\begin{array}{l}\text { Sediment } \\
\text { Samples }\end{array}$ & Sampling Area & pH & Conductance $(\mu \mathrm{S} / \mathrm{cm})$ & $\begin{array}{l}\text { TOC } \\
(\mathrm{g} / 100 \mathrm{~g})\end{array}$ & $\begin{array}{c}\text { Moisture } \\
\text { Content (\%) }\end{array}$ & $\begin{array}{c}\text { Ash Content } \\
(\%)\end{array}$ & $\begin{array}{c}\text { Cr content } \\
(\mathrm{mg} / \mathrm{kg})\end{array}$ \\
\hline S-02 & & 5.29 & 374.00 & 1.52 & 27.42 & 5.31 & 47.89 \\
\hline S-04 & & 5.68 & 34.70 & 2.33 & 26.14 & 3.85 & 49.96 \\
\hline S-05 & & 6.01 & 24.60 & 3.10 & 25.45 & 4.50 & 39.64 \\
\hline S-06 & & 5.70 & 28.60 & 1.88 & 29.10 & 5.20 & 41.49 \\
\hline S-09 & & 5.20 & 60.80 & 2.67 & 27.22 & 3.69 & 44.63 \\
\hline S-10 & & 5.85 & 65.90 & 2.28 & 24.90 & 5.10 & 45.12 \\
\hline S-11 & & 6.10 & 60.90 & 1.95 & 25.60 & 4.70 & 68.56 \\
\hline S-12 & & 6.06 & 65.40 & 3.25 & 28.17 & 4.32 & 44.63 \\
\hline S-13 & Jauchor point-1 & 5.97 & 53.20 & 2.15 & 27.49 & 4.07 & 63.28 \\
\hline S-14 & & 5.48 & 77.40 & 2.41 & 29.13 & 5.40 & 100.58 \\
\hline S-19 & & 6.02 & 80.60 & 3.04 & 23.90 & 5.80 & 127.78 \\
\hline S-20 & & 6.12 & 103.40 & 3.21 & 23.45 & 5.39 & 234.68 \\
\hline
\end{tabular}

Table 3. Metal ions content in water samples (mg/kg)

\begin{tabular}{|c|c|c|c|c|c|}
\hline Water Samples & Sampling Area & $\mathrm{Cr}$ & $\mathbf{C a}$ & $\mathbf{N a}$ & $\mathbf{K}$ \\
\hline $\mathrm{W}-01$ & \multirow{3}{*}{ Rim jhim point-1 } & $<0.005$ & 23.58 & 35.90 & BDL \\
\hline $\mathrm{W}-03$ & & $<0.005$ & 27.36 & 45.00 & BDL \\
\hline W-05 & & $<0.005$ & 23.58 & 31.36 & BDL \\
\hline W-06 & \multirow{3}{*}{ Rim jhim point-2 } & $<0.005$ & 19.81 & 40.45 & BDL \\
\hline W-07 & & $<0.005$ & 16.04 & 31.36 & BDL \\
\hline $\mathrm{W}-10$ & & $<0.005$ & 19.81 & 26.81 & BDL \\
\hline $\mathrm{W}-11$ & \multirow{5}{*}{ Jauchor point-1 } & \multirow{6}{*}{$\begin{array}{l}\vec{D} \\
\stackrel{0}{0} \\
0 \\
0 \\
0 \\
0 \\
0\end{array}$} & 23.58 & 40.45 & BDL \\
\hline W-12 & & & 27.36 & 35.90 & BDL \\
\hline $\mathrm{W}-13$ & & & 23.58 & 40.45 & BDL \\
\hline W-14 & & & $\begin{array}{l}25.50 \\
23.58\end{array}$ & $\begin{array}{l}40.4 J \\
40.45\end{array}$ & $\begin{array}{l}\text { DDL } \\
\text { BDL }\end{array}$ \\
\hline $\mathrm{W}-15$ & & & 19.81 & 35.90 & $\mathrm{BDL}$ \\
\hline $\mathrm{W}-20$ & Jauchor point-2 & & 27.36 & 35.90 & BDL \\
\hline
\end{tabular}

Ten water samples from different sources were analyzed for $\mathrm{Cr}$ and were found below $0.005 \mathrm{mg} / \mathrm{L}$. The standard limit of $\mathrm{Cr}$ in water is $0.05 \mathrm{mg} / \mathrm{L}{ }^{44,45}$ Ahsan et al. reported that the concentration of $\mathrm{Cr}$ is $<0.005 \mathrm{mg} / \mathrm{L}$ in Dhaleshwari river which is closest to this study. The very low concentration of $\mathrm{Cr}$ is may be due to the stream of river water. ${ }^{17}$ Amount of $\mathrm{Na}, \mathrm{Ca}$ and $\mathrm{K}$ ions were analyzed by flame photometer and found in the order of $\mathrm{Na}(26.81-45.00 \mathrm{mg} / \mathrm{L})>\mathrm{Ca}(16.04-$ $27.36 \mathrm{mg} / \mathrm{L})>\mathrm{K}$ (BDL) ions(Table 3). The permissible level of $\mathrm{Na}$ and $\mathrm{K}$ ions are 175 and $10 \mathrm{mg} / \mathrm{L}$, respectively $(\mathrm{EC})^{46}$ which indicates that all the values are in below permissible limit.

Pearson Correlation ( $r$-value) matrix Table 4 and table 5 elucidate the interconnected relationships among the different physiochemical parameters of water and sediment samples, respectively. In in table 4 , the DO of the water sample inhibits a positive significant correlation with $\mathrm{Ca}$ Hardness $(r=0.580$ and $p=0.007)$ as well as with TSS $(r=$ 0.563 and $p=0.010)$. Whether, BOD is shows a negative significant correlation with DO $(r=-0.519$ and $p=0.019)$ which indicate that BOD is inversely proportional to DO.

Additionally, in other parameters show some positive and negative interconnection among them but which are not significant statistically. This result suggested that several unused chemicals and tannery waste discharged from the tannery industries are reducing DO in the river water through increasing TSS which causes turbidity in water by disrupting different photosynthetic actions. As a result turbidity stimulate to rise up the conductance. Furthermore, BOD is rapidly increasing through reduction of DO in river water. 
Table 4. Pearson Correlation (r) matrix of physiochemical parameters of the water samples

\begin{tabular}{llllllll}
\hline & pH & Conductance & TOC & Ca Hardness & DO & BOD & TSS \\
\hline pH & 1 & & & & & & \\
Conductance & 0.357 & 1 & & & & & \\
TOC & -0.104 & -0.274 & 1 & & & & \\
Ca Hardness & -0.081 & -0.010 & -0.220 & 1 & 1 & & \\
DO & 0.152 & -0.059 & -0.156 & $\mathbf{0 . 5 8 0 * *}$ & $-0.519^{* *}$ & 1 & 1 \\
BOD & 0.259 & 0.288 & 0.347 & -0.300 & $\mathbf{0 . 5 6 3 * *}$ & -0.384 & 1 \\
TSS & 0.064 & -0.073 & -0.297 & 0.408 & & \\
\hline
\end{tabular}

** Correlation is significant at the 0.01 level (2-tailed), * Correlation is significant at the 0.05 level (2-tailed).

Table 5. Pearson Correlation ( $r$ ) matrix of physiochemical parameters and $\mathrm{Cr}$ of the sediment samples

\begin{tabular}{|c|c|c|c|c|c|c|}
\hline & $\mathrm{pH}$ & Conductance & TOC & Moisture & Ash Content & Cr content \\
\hline pH & 1 & & & & & \\
\hline TOC & 0.311 & $-0.496^{*}$ & 1 & & & \\
\hline Ash Content & -0.119 & 0.237 & 0.199 & -0.200 & 1 & \\
\hline Cr content & -0.072 & 0.029 & 0.171 & 0.018 & 0.284 & 1 \\
\hline
\end{tabular}

*. Correlation is significant at the 0.05 level (2-tailed).

However, in case of sediment sample, conductance shows negative significant correlation with $\mathrm{pH}(r=-0.500$ and $p=$ $0.025)$ and TOC is significantly negative correlated with conductance $(r=-0.496$ and $p=0.026)$ (Table 5). That means conductance is inversely proportional to $\mathrm{pH}$ and TOC is inversely proportional to conductance. It may be occurred directly release of ternary and other industrial waste into environment which can increase the TOC level usually. Statistically any remarkable correlation is not observed in $\mathrm{Cr}$ content including other parameters although some alterations are noticed among them. This finding indicates that due to the reduction of conductance through enhancement of TOC level gradually the $\mathrm{pH}$ level is diverging in the sediment of river side. Therefore, it may concluded that due to the discharging of unused chemical and directly releasing of ternary and other industrials waste gradually increase the TOC, $\mathrm{pH}$ and $\mathrm{BOD}$ through the decreasing of DO level in the river water and river side sediment.

\section{Conclusions}

According to this study it was found that water quality parameters varied with different locations of the collected samples. The average $\mathrm{pH}$ values of sediment below the neutral condition and that for water was higher than neutral condition. The average EC of the collected water was much higher than surface water. The DO levels were lower than the permissible limit that indicates the water samples were not well oxygenated. The BOD levels were found higher that is an indicator of polluted water. The low TOC values of water indicate that water might contain fewer amounts of plant and animal residues, root exudates and organochlorine pesticides etc. The concentrations of $\mathrm{Cr}$ in water samples was very insignificant level and below the detection limit but significantly high in sediments samples. Savar industrial area has established in recent years but our study indicates that it may affect the ecosystem of river in near future unless the respective authority takes measures.

\section{Acknowledgement}

The authors are grateful to International Science Programme (ISP) Uppsala University, Sweden for financial supports

\section{References}

1. Ahamed, M., 2014. A Report on Leather and Leather Goods Industry of Bangladesh. JB Group Research Department, JBBC Corporation.

2. Akter, S., Kamrujjaman, Rashed-Ul-Islam, and B. Saha, 2019. An Investigation into Chemical Parameters of Water of Dhaleswari - A River alongside Tannery Village of Bangladesh. Int. J. of Sci., 8(5), 159-164.

3. Khwaja, A.R., 1998. Studies on Pollution Abatement of Wastes from Leather Industries, $P h D$ thesis, University of Roorkee India.

4. Jahan, M. A. A., N. Akhtar, N. M. S. Khan, C. K. Roy, R.. Islam, and Nurunnabi, 2014. Characterization of tannery wastewater and its treatment by aquatic macrophytes and algae. Bangladesh J. Sci. Ind. Res. 49(4), 233-242.

5. UNEP IE/PAC, 1994. Tanneries and the Environment - A Technical Guide, Technical Report (2nd Print) Series No 4.

6. Mwinyihija, M., 2012. Pollution Control and Remediation of the Tanning Effluent. The Open Environ. Pollution and Tox. $J ., 3,55-64$.

7. Rajeswari, A., 2015. Efficiency of effluent treatment plant and assessment of water quality parameters in tannery wastes. Pelagia Research Library, Europ. J. of Exp. Biology, ISSN: $2248-9215,5(8), 49-55$.

8. Gowd, S., R. M. Reddy, and P.K. Govil, 2010. Assessment of heavy metal contamination in soils at Jajmau (Kanpur) and Unnao industrial areas of the Ganga Plain, Uttar Pradesh, India. J Hazard Mat., 174, 113-121.

9. Tariq, S.R., M.H. Shah, N. Shaheen, A. Khalique, S. Manzoor, and M., Jaffar, 2005. Multivariate analysis of selected metals in tannery effluents and related soil. $J$ Hazard Mater 122, 17-22.

10. Sallam, A.S., A.R. A. Usman, A.A. Hassan, M. I. Al-Wabel, and A. Al-Omran, 2015. Environmental assessment of tannery 
wastes in relation to dumpsite soil: a case study from Riyadh, Saudi Arabia. Arab. J. of Geosciences, doi: 10.1007/s12517-0151956-7.

11. Tariq, S.R., M.H., Shah, N. Shaheen, A. Khalique, S. Manzoor, and M. Jaffar, 2006. Multivariate analysis of trace metal levels in tannery effluents in relation to soil and water: a case study from Peshawar, Pakistan. J Environ Manag 79, 20-29.

12. Developing the Leather Industry in Bangladesh, Soon Chan Hong Senior Economist South Asia Department Asian Development Bank, November 2018, ADB BRIEFSNO.102 (1-8).

13. The Daily Star, August 03, 2019. Savar tannery waste taints dhaleshwari River in Bangladesh-1781059.

14. The Financial Express, September 30, 2018 17:46:57. National tannery-wastes-polluting Dhaleshwari-1538308017.

15. Daily Sun, 27 December, 2017. Tanneries now ruining Dhaleshwari.

16. The New Nation, 09th-Jan-2018. Now tannery wastes polluting Dhaleshwari.

17. Ahsan, M.A., M.A.B. Siddique, M.A. Munni, M.A. Akbor, S. Akter, and M.Y. Mia, 2018. Analysis of Physicochemical Parameters, Anions and Major Heavy Metals of the Dhaleshwari River Water, Tangail, Bangladesh. Amer. J. of Environ. Protec. doi: 10.11648/j.ajep.20180702.12, 7 (2), 29-39.

18. Parveen, S., R. Bharose, and D. Singh, 2017. Assessment of Physico-Chemical Properties of Tannery Waste Water and Its Impact on Fresh Water Quality. Int.J.Curr.Microbiol.App.Sci. doi: https://doi.org/10.20546/ijcmas.2017.604.224, 6(4), 1879-1887.

19. Sawyer, C.N., P.L. McCarty, and G.F. Parkin, 2003. Chemistry for Environmental Engineering and Science, McGraw-Hill, New York, 5th edition.

20. Hseu, Z.Y., Z.S. Chen, C.C. Tsai, et al., 2002. Digestion Methods for Total Heavy Metals in Sediments and Soils. Water, Air, and Soil Pollution, 141, 189-205.

21. Sugasini, A. and K. Rajagopal, 2015. Characterization of Physicochemical Parameters and heavy metal Analysis of Tannery Effluent. Int. J. of Current Microb. and App. Sciences ISSN: 2319-7706, 4, 349-359.

22. Saxena, S. and P. Shrivastava, 2002. Ground water quality of a typical urban settlement: A case study of impact of town planning. Pollut. Res., 21, 223-226.

23. European Union, 1989. European Communities Regulations: Quality of surface water intended for the abstraction of drinking water. Serial no. 294.

24. Das, B., 1997. Fisheries Res. Management in Bangladesh. Bangla Academy, Dhaka, Bangladesh, 153-155.

25. HORIBA, Soil $\mathrm{pH}$ and Nutrient Availability, Application Note, 07-2015.

26. USDA (U. S. Department of Agriculture), Soil Quality Information Sheet, USDA Natural Resources Conservation Service, January, 1998.

27. WHO (World Health Organization), Guidelines for Drinking water Quality, 1984, 51.

28. ECR (The Environment Conservation Rules), Ministry of Environment and Forest, Government of the People's Republic of Bangladesh, Bangladesh. 1997.
29. Jamal, M., S. Dawood, S. Nausheenawood, and B.K. Ilango, 2011. Characterization of tannery effluent. J. Ind. Pollut.Control, 20, 1-6.

30. Akan, J.C., F.I.A. Rahman, G.A. Dimari, and V.O. Ogugbuaja, 2008. Physiological determination of pollutants in waste water and vegetables samples along the Jakara waste water channel in Kano metropolis, Kano state, Nigeria. Eur. J. Sci. Res., 23, 122-133.

31. Matus, J., Francisco, Escudey, Mauricio, Förster, E. Juan, Gutiérrez, Marlen, Chang, and C. Andrew, 2009. Is the Walkley-Black Method Suitable for Organic Carbon Determination in Chilean Volcanic Soils? Communications in Soil Science and Plant Analysis, 40, 11,1862-872.

32. Wurts, W.A., 2016. Understanding Water Hardness, 27 August 2016.

33. WHO, 2002. Water pollutants: Biological agents, Dissolved chemicals, Non dissolved chemicals, Sediments, Heat, WHO CEHA, Amman, Jordan.

34. Kulkarni, R.T., 1992. Source and characteristics of dairy wastes from a medium sized effluent on microorganisms, plant growth and their microbial change. Adv. Life Sci., 3, 76-86.

35. Noorjahan, C.M., S.D. Sharief, and D. Nausheen, 2004. Characterization of dairy effluent. J. Ind. Pollut.Control, 20 , 131136.

36. Islam, M.S., N.T.M. Suravi, S.A. Mamun, and M. Islam, 2012. Status of water quality in the Dhaleshwari River and its effect on aquatic organism, J. of Environ. Sci. and Water Resources, 1, 192-201.

37. Goel, P.K., 2000. Water pollution causes effects and control. New Age Int. Pub. Ltd., Publ. New Delhi 269.

38. Chakrapani, G.J., 2005. Major trace element geochemistry in upper Ganga river in the Himalayas, India. Environ. Geol., 48, 189-201.

39. Mondol, M.N., A. Asia, A.S. Chamon, and S.M.A. Faiz, 2017. Contamination of soil and plant by the hazaribagh tannery industries. J. Asiat. Soc. Bangladesh, Sci. 43(2), 207222.

40. Belay, A.A., 2010. Impacts of Chromium from Tannery Effluent and Evaluation of Alternative Treatment Options. J. of Environ. Protection., doi: 10.4236/jep.2010.11007, 1, 53-58.

41. Sundar, V.J., J. R. Rao, and C. Muralidharan, 2002. Cleaner chrome tanning-emerging options, J. of cleaner produc., 10 , 69-74.

42. Mottalib, M.A., S.H. Somoal, M.A.A. Shaikh, and M.S Islam, 2016. Heavy metal conc. in contaminated soil and vegetables of tannery area in Dhaka, Bangladesh. Int. J. Curr. Res., 8, (5), 30369-30373.

43. Coskun, M., E., Steinnes, and F. Viladimirovna, 2006. Heavy metal pollution of surface soil in the thrace region, Turkey. Environ. Monit. Assess, 119, 545-556.

44. BSTI (Bangladesh Standards and Testing Institute), 2001. BDS1240.

45. ECR (The Environment Conservation Rules), 1997. Ministry of Environment and Forest, Government of the People's Republic of Bangladesh, Bangladesh.

46. European Community (EC), 1986. Guidelines for drinking water quality. 